ORIGINAL ARTICLE

\title{
Lymph node harvests directly influence the staging of colorectal cancer: evidence from a regional audit
}

\author{
D F H Pheby, D F Levine, R W Pitcher, N A Shepherd
}

See end of article for authors' affiliations

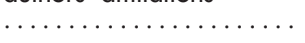

Correspondence to: Dr D F H Pheby, Unit of Applied Epidemiology, University of the West of England, Frenchay Campus, Coldharbour Lane, Bristol, BS16 1QY, UK; derek.pheby@ uwe.ac.uk

Accepted for publication 12 June 2003

\begin{abstract}
Aims: To assess the quality of histopathology reporting and accuracy of Dukes's staging of colorectal cancers in the former South Western Health region and to determine the impact of numbers of lymph nodes examined on stage ascription.

Methods: Histopathology reports of colorectal cancer for 1993-7 were analysed. Completeness was assessed regarding reported numbers of lymph nodes examined, numbers found positive, Dukes's stage, and ICD9 code. Numbers of lymph nodes examined, numbers found positive, and Dukes's stage were recorded. Results from one hospital known to have high standards of reporting were compared with those from elsewhere.

Results: In total, 629 reports were examined from the reference hospital and 918 from elsewhere. Fewer than one in 20 (4.3\%) reports from the reference hospital were incomplete, compared with a third (36.1\%) elsewhere. The average number of nodes examined for each case at the reference hospital was 18.81 and 6.41 elsewhere. The average number of positive nodes for each case was 2.47 at the reference hospital and 1.15 elsewhere. The proportion of Dukes's stage C cases was significantly higher at the reference hospital than elsewhere. Ascertainment of Dukes's stage $C$ cases was related to number of lymph nodes examined, with optimal ascertainment levels when at least 10 and fewer than 15 nodes were examined. Conclusions: Standards of histopathology reporting, and ascertainment of Dukes's stage C, were significantly higher at the reference hospital. Variations in ascertainment levels of Dukes's stage C disease mainly resulted from variations in the numbers of lymph nodes examined.
\end{abstract}

mproving the quality of services for colorectal cancer is a national priority. National performance indicators have been defined, including the quality of pathology, and one of the objectives of the National standards for cancer treatment is "pathology reports conforming to Royal College of Pathologist's recommendations for individual cancer sites". ${ }^{1}$ The Royal College of Pathologist's minimum dataset includes number of lymph nodes examined and the number found positive. It recommends that all lymph nodes draining the lymphatic field of a colorectal cancer should be harvested for histological assessment. ${ }^{2}$

The incidence of colorectal cancer has increased greatly in recent years. For example, in 1992 the incidence of colon cancer for each 100000 population had risen to 34.16 from 22.47 in men in 1973, and to 38.10 from 29.58 in women. ${ }^{3} \mathrm{~A}$ total of 25000 cases of colorectal cancer occur annually in the UK; $80 \%$ are resected surgically. ${ }^{4}$ There are resource problems associated with this large and increasing workload. Pollock et al have drawn attention to the extent to which the relative risk of not being treated increased between 1982 and 1988 in the South Thames regions. ${ }^{5}$ The increasing workload is undoubtedly a major factor in explaining the results of an audit of histopathology laboratories in Wales during 1993, which indicated that the information content of many reports was inadequate for high quality patient management or clinical audit. ${ }^{6}$ For example, only $51.5 \%$ of rectal cancer reports indicated completeness of excision, and only $30 \%$ of all reports stated the number of involved lymph nodes. Overall, only $11.3 \%$ of reports on colonic tumours and $4.0 \%$ of reports on rectal tumours contained all previously agreed data items. ${ }^{6}$

European cancer registry based comparisons suggest that there may be inadequate treatment of patients with colorectal cancer in the UK. However, it has been intimated that the poor UK survival rates can be explained by more advanced stage at presentation, although this has been challenged. ${ }^{7}$ The EUROCARE study indicated that there was still a twofold variation in survival rates after adjustment for variations in stage distribution. ${ }^{8}$ An Italian study has shown that survival improvements between 1984 and 1995 were related to an increasing proportion of early stage disease. ${ }^{9}$ However, tumours may be understaged and hence excluded from certain forms of treatment, such as adjuvant treatment, through failure to identify lymph node involvement. ${ }^{10}$

\footnotetext{
"Because the classification of a cancer as Dukes's $C$ is wholly determined by lymph node involvement, the importance of accurate lymph node assessment is irrefutable"
}

Delays in diagnosis and treatment probably result in tumours being more advanced when treatment is begun. More advanced stage is associated with poorer survival. The National Health Service Executive guidance on improving outcomes in colorectal cancer reports a case series from Dublin in which around $30 \%$ of patients presented with Dukes's stage C cancers; among these, five year survival was about $30 \%,{ }^{11}$ although this could be improved with protracted systemic chemotherapy. ${ }^{11}$ In that regard, Dukes's staging remains the single most important determinant of the decision to institute adjuvant chemotherapy in younger, fitter patients. Thus, systemic chemotherapy is generally indicated for Dukes's C cancers, whereas the indications for such treatment in Dukes's B cancers are more uncertain. ${ }^{12}$ Because the classification of a cancer as Dukes's C is wholly determined by lymph node involvement, the importance of accurate lymph node assessment is irrefutable.

There are pronounced variations between pathologists in ascription of resection specimens to Dukes's stage A or B on 
Table 1 Hospital A versus the other hospitals: incomplete records

\begin{tabular}{|c|c|c|c|c|c|}
\hline \multirow[b]{2}{*}{ Records } & \multicolumn{2}{|l|}{ Hospital A } & \multicolumn{2}{|c|}{ Other hospitals } & \multirow[b]{2}{*}{ Total } \\
\hline & No. cases & $\%(95 \% \mathrm{Cl})$ & No. cases & $\%(95 \% \mathrm{Cl})$ & \\
\hline Incomplete report & 27 & $4.30(2.68$ to 5.92$)$ & 331 & $36.10(32.92$ to 39.27$)$ & 358 \\
\hline $\begin{array}{l}\text { Suboptimal record of nodes examined, } \\
\text { nodes positive, and Dukes's stage }\end{array}$ & 10 & $1.59(0.59$ to 2.59$)$ & 161 & $17.56(15.04$ to 20.07$)$ & 171 \\
\hline No record of Dukes's stage but can be inferred & 1 & $0.16(0.00$ to 0.48$)$ & 42 & $4.58(3.20$ to 5.96$)$ & 43 \\
\hline $\begin{array}{l}\text { No record of nodes examined/positive } \\
\text { but Dukes's stage given }\end{array}$ & 9 & $1.43(0.48$ to 2.38$)$ & 35 & 3.82 ( 2.55 to 5.08 ) & 44 \\
\hline $\begin{array}{l}\text { Nodes examined and nodes positive recorded } \\
\text { but Dukes's stage not given }\end{array}$ & 0 & 0.00 & 24 & 2.62 (1.56 to 3.67$)$ & 24 \\
\hline Missing ICD code & 11 & $1.75(0.70$ to 2.80$)$ & 57 & $6.22(4.62$ to 7.81$)$ & 68 \\
\hline Total & 628 & 100.0 & 917 & 100.0 & 1545 \\
\hline
\end{tabular}

the one hand, or Dukes's C on the other. ${ }^{4}{ }^{13}$ Improvements in accuracy may result from following standardised specimen examination methods, ${ }^{14}{ }^{15}$ including formal proformas. ${ }^{16}{ }^{17}$ It has been suggested that peroperative lymphatic mapping and identification of sentinel lymph nodes may lead to improvements in staging ${ }^{18}$ and more tailored resections. ${ }^{19}$ In one study, such an approach resulted in upstaging $18 \%$ of patients. $^{20}$

There have been several studies that have arrived at different conclusions regarding the number of lymph nodes that should be examined to ensure accurate stage ascription. The recommendations of these studies differ in detail, partly but not entirely because different criteria have been adopted, but generally agree that the more extensive the lymph node harvest the greater is the chance of discovery of metastatic disease within those lymph nodes.

\section{METHODS}

Our study was undertaken in the former South Western Health region to assess the accuracy of Dukes's staging in colorectal cancer. This was accomplished by comparing results achieved in one hospital that was known to have achieved a high standard of accuracy in this regard (henceforth "hospital $\mathrm{A}^{\prime \prime}$ ) with data from other hospitals in the region. The enquiry had two main foci: (1) the quality of histopathology reporting and (2) the assignment of cases to Dukes's stages A or B, on the one hand, and stage $\mathrm{C}$ on the other, and the impact on stage ascription of numbers of lymph nodes examined.

Histopathology reports relating to cases of colorectal cancer were collected from hospitals across the region, for the five year period 1993-7, through the South Western Regional Cancer Registry and also by direct contact with laboratories. Completeness was assessed in respect of numbers of lymph nodes examined and numbers found positive, Dukes's stage, and site code (ICD9). For those reports where sufficient detail was recorded, numbers of lymph nodes examined, numbers found positive, and Dukes's stage were recorded. Results in the exemplar site, hospital A, were compared with those elsewhere in the region.

There were 629 reports available from hospital A and 918 from the other hospitals. The comparability of the cases drawn from hospital A and the other hospitals was assessed by studying the distribution of numbers of cases by ICD9 site codes in the two groups. Numbers of lymph nodes examined in the two groups of cases were recorded. Mean values and 95\% confidence intervals (CI) were calculated and a MannWhitney test of rank distribution carried out. The proportions of cases with Dukes's C staging were ascertained in the two groups and the extent to which differences could be explained by variations in the number of lymph nodes examined was determined.

\section{RESULTS}

Overall, 629 reports were examined from hospital A, of which 27 were incomplete in some respect, whereas 918 reports were examined from the other hospitals, of which 331 were incomplete. Table 1 summarise the results in respect of completeness. There were large and significant differences between the reference hospital and the others. Overall, more than a third $(36.1 \%)$ of the records from hospitals other than the reference hospital were incomplete in one or more aspect, compared with fewer than one in $20(4.3 \%)$ at the reference hospital.

The distribution of numbers of cases by ICD9 site code was similar in hospital A and the other hospitals, indicating that the two patient populations were broadly comparable. There was a very substantial difference between hospital A and the other hospitals in numbers of lymph nodes examined (table 2). The average number of nodes examined for each patient at hospital A was 18.81 (95\% CI, 18.07 to 19.55), whereas at the other hospitals it was 6.41 (95\% CI, 6.09 to 6.73). A similar significant difference was also seen for numbers of positive lymph nodes encountered (table 3 ), the average number for each patient at hospital A being 2.47 (95\% CI, 2.11 to 2.83 ) and at other hospitals 1.15 (95\% CI, 0.08 to 1.31). However, a Mann-Whitney test of rank

\begin{tabular}{|c|c|c|c|c|c|}
\hline \multirow{2}{*}{$\begin{array}{l}\text { Number of } \\
\text { nodes examined }\end{array}$} & \multicolumn{2}{|l|}{ Hospital A } & \multicolumn{2}{|c|}{ Other hospitals } & \multirow[b]{2}{*}{ Total } \\
\hline & No. patients & $\%(95 \% \mathrm{Cl})$ & No. patients & $\%(95 \% \mathrm{Cl})$ & \\
\hline $1-9$ & 88 & $14.55(11.68$ to 17.41$)$ & 498 & 80.32 (77.13 to 83.52 ) & 586 \\
\hline $10-14$ & 129 & $21.32(17.99$ to 24.65$)$ & 89 & 14.35 (11.54 to 17.17$)$ & 218 \\
\hline $15-19$ & 131 & 21.65 (18.30 to 25.00$)$ & 27 & 4.35 (2.72 to 5.99$)$ & 158 \\
\hline 20 or more & 257 & 42.48 (38.46 to 46.50$)$ & 6 & $0.97(0.18$ to 1.75$)$ & 263 \\
\hline Total & 605 & 100.0 & 620 & 100.0 & 1225 \\
\hline
\end{tabular}

$\mathrm{Cl}$, confidence interval. 


\begin{tabular}{|c|c|c|c|c|c|}
\hline \multirow{2}{*}{$\begin{array}{l}\text { Number of positive } \\
\text { nodes encountered }\end{array}$} & \multicolumn{2}{|l|}{ Hospital A } & \multicolumn{2}{|c|}{ Other hospitals } & \multirow[b]{2}{*}{ Total } \\
\hline & No. patients & $\%(95 \% \mathrm{Cl})$ & No. patients & $\%(95 \% \mathrm{Cl})$ & \\
\hline 0 & 305 & 50.83 (46.75 to 54.92 ) & 411 & $58.38(54.67$ to 62.10$)$ & 716 \\
\hline $1-4$ & 181 & $30.17(26.42$ to 33.91$)$ & 247 & 35.09 (31.49 to 38.68$)$ & 428 \\
\hline $5-9$ & 77 & $12.83(10.10$ to 15.56$)$ & 38 & $5.40(3.69$ to 7.10$)$ & 115 \\
\hline $10-14$ & 19 & $3.17(1.74$ to 4.60$)$ & 7 & $0.99(0.25$ to 1.74$))$ & 26 \\
\hline $15-19$ & 5 & $0.83(0.09$ to 1.58$)$ & 1 & $0.14(0.00$ to 0.43$))$ & 6 \\
\hline $20-24$ & 10 & $1.67(0.62$ to 2.71$)$ & 0 & - & 10 \\
\hline $25-29$ & 1 & $0.17(0.00$ to 0.50$)$ & 0 & - & 1 \\
\hline $30-34$ & 2 & $0.33(0.00$ to 0.80$)$ & 0 & - & 2 \\
\hline Total & 600 & 100.0 & 704 & 100.0 & 1304 \\
\hline
\end{tabular}

distribution showed no association between numbers of lymph nodes examined and the likelihood of having lymph node involvement. This may be because it is a test of difference in central tendency between two groups and does not work well if they differ without a difference in average rank position, as in this case, where node negative cases appear to form a higher proportion of cases in both the higher and the lower ranks.

The proportion of Dukes's stage C cases was 7.95\% higher at the reference hospital than elsewhere $(50.24 \%$ at hospital A; $42.29 \%$ elsewhere). This was significant at the $95 \%$ level (table 4). Ascertainment of Dukes's stage C cases was related to the number of lymph nodes examined, with optimal ascertainment levels occurring when at least 10 and fewer than 15 nodes were examined. This was true at both hospital A and the other hospitals (table 5). The proportion of cases from hospital A was closely correlated with the number of nodes examined ( $R=0.967$; explained variation, 93.5\%), whereas $68.7 \%$ of the overall variation in the proportion of Dukes's stage C tumours with numbers of lymph nodes examined can be explained as being the result of variations in the proportion of cases from hospital $\mathrm{A}(R=0.828)$.

\section{DISCUSSION}

In our study, the observed variation in pathological reporting quality is consistent with other studies, which have concluded that standard proformas and more precisely defined staging may be appropriate. ${ }^{21}$ There is general agreement on the need to improve standards of reporting, in particular stage ascription, to improve clinical care, and of the benefits of standard protocols, such as that of the Cancer Committee of the College of American Pathologists. ${ }^{22}$ Following the Welsh audit, suggestions for improving the quality of pathological reporting included the use of template proformas, ${ }^{6}$ to improve among other things the quality of clinical decision making, especially the use of postoperative adjuvant treatment. ${ }^{23}$ Indeed, more recent evidence has confirmed that the routine use of proformas substantially improves the recording of relevant data. ${ }^{17}$ Much of the inadequacy of colorectal cancer reporting has been attributed to poor teaching in macroscopic assessment, resulting in inadequate lymph node harvesting, poor evaluation of local spread, and unsatisfactory determination of margin and serosal involvement. $^{4}$

In our study, the number of Dukes's C cases was significantly higher (by about $8 \%$ ) in the reference hospital than in the other hospitals. Thus, it seem likely that, in the former South Western Health region, excluding the population served by hospital A, approximately 160 stage $C$ cases each year might have been understaged in this time period. This has serious implications, because staging remains the most important prognostic factor in colorectal cancer. Furthermore, accurate staging is a very important prerequisite for effective treatment. Thus, adjuvant chemotherapy, which has been proved to be of benefit in patients with Dukes's stage C colorectal cancer, ${ }^{24}$ has been associated with a $34 \%$ improvement in disease free interval and a $29 \%$ improvement in survival. ${ }^{25}$ This has been endorsed by the National Health Service Executive's guidance on improving outcomes, which also argues that there is insufficient evidence from randomised controlled trials to form a definitive view on chemotherapy in stage B disease. ${ }^{11}$ More recently, data from one of our centres has suggested that accurate pathological assessment can successfully stratify Dukes's B colon cancers, at least, for prognosis, which may aid in the selection of appropriate patients for adjuvant treatment. ${ }^{12}$ It should also be noted that the effect of understaging is to reduce artefactually the stage specific survival of both stage $B$ and stage $C$ patients, through the phenomenon of stage drift.

For both the exemplar hospital and the others, the ascertainment of Dukes's stage C disease was highest when 10 to 14 lymph nodes were examined. Examination of greater numbers of lymph nodes brought no further improvement in ascertainment levels. Ascertainment levels were lowest when fewer than 10 lymph nodes were examined. The overall difference in ascertainment of stage $\mathrm{C}$ disease between the exemplar hospital and the others is mainly the result of the fact that $80.32 \%$ of cases treated at other hospitals came into the category of low lymph node harvests, compared with only $14.55 \%$ of cases treated at hospital A.

Table 4 Hospital A versus the other hospitals: distribution of cases by Dukes's stage

\begin{tabular}{|c|c|c|c|c|c|}
\hline \multirow{2}{*}{$\begin{array}{l}\text { Dukes's } \\
\text { stage }\end{array}$} & \multicolumn{2}{|l|}{ Hospital A } & \multicolumn{2}{|c|}{ Other hospitals } & \multirow[b]{2}{*}{ Total } \\
\hline & No. cases & $\%(95 \% \mathrm{Cl})$ & No. cases & $\%(95 \% \mathrm{Cl})$ & \\
\hline $\begin{array}{l}A \text { and } B \\
C\end{array}$ & 307 & 49.76 (45.73 to 53.78$)$ & 419 & $\begin{array}{l}57.71(54.05 \text { to } 61.38) \\
42.29(38.62 \text { to } 45.94)\end{array}$ & $\begin{array}{l}726 \\
617\end{array}$ \\
\hline & $\begin{array}{l}310 \\
617\end{array}$ & $\begin{array}{l}50.24(46.22 \text { to } 54.27) \\
100.0\end{array}$ & $\begin{array}{l}307 \\
726\end{array}$ & $\begin{array}{l}42.29 \text { (38.62 to } 45.94) \\
100.0\end{array}$ & $\begin{array}{r}617 \\
1343\end{array}$ \\
\hline
\end{tabular}

$\mathrm{Cl}$, confidence interval. 
Table 5 Percentage of Dukes's stage C cases, by number of nodes examined, for hospital A and the other hospitals

\begin{tabular}{|c|c|c|c|c|c|c|}
\hline \multirow[b]{2}{*}{ Hospital } & \multirow{2}{*}{$\begin{array}{l}\text { Number } \\
\text { of nodes }\end{array}$} & \multirow{2}{*}{$\begin{array}{l}\text { Total } \\
\text { number } \\
\text { of cases }\end{array}$} & \multicolumn{2}{|l|}{ Dukes A/B } & \multicolumn{2}{|l|}{ Dukes C } \\
\hline & & & No. cases & \% Total $(95 \% \mathrm{Cl})$ & No. cases & $\%$ Total $(95 \% \mathrm{Cl})$ \\
\hline \multirow[t]{5}{*}{ A } & $1-9$ & 88 & 52 & 59.09 (48.61 to 69.57$)$ & 36 & $40.91(30.43$ to 51.39$)$ \\
\hline & $10-14$ & 129 & 50 & 38.76 (30.18 to 47.34$)$ & 79 & 61.24 (52.66 to 69.82$)$ \\
\hline & $15-19$ & 131 & 67 & 51.15 (42.41 to 59.88 ) & 64 & 48.8540 .12 to 57.59$)$ \\
\hline & $\geqslant 20$ & 257 & 131 & 50.97 (44.74 to 57.21$)$ & 126 & 49.03 (42.79 to 55.26$)$ \\
\hline & Total & 605 & 300 & 49.59 ( 45.54 to 53.65$)$ & 305 & 50.41 (46.35 to 54.48$)$ \\
\hline \multirow[t]{5}{*}{ Others } & $1-9$ & 498 & 291 & $58.43(54.02$ to 62.85$)$ & 207 & 41.57 (37.15 to 45.98 ) \\
\hline & $10-14$ & 89 & 44 & 49.44 (38.84 to 60.04$)$ & 49 & 55.06 (38.44 to 60.04$)$ \\
\hline & $15-19$ & 27 & 14 & 51.85 (32.62 to 71.08$)$ & 13 & 48.15 (28.92 to 67.38 \\
\hline & $\geqslant 20$ & 6 & 3 & $50.00(9.18$ to 90.82$)$ & 3 & $50.00(9.18$ to 90.82$)$ \\
\hline & Total & 620 & 352 & $56.77(52.80$ to 60.75$)$ & 272 & 43.87 (39.89 to 47.86$)$ \\
\hline
\end{tabular}

Table 6 Recommendations about numbers of lymph nodes to examine in colorectal cancer resection specimens

\begin{tabular}{|c|c|c|c|}
\hline Fist author (Ref) & Year of publication & Study objective & No. lymph nodes \\
\hline Hermanek $^{26}$ & 1993 & $\begin{array}{l}\text { Maximise ascertainment of Dukes's stage C } \\
\text { disease }\end{array}$ & $20+$ \\
\hline Goldstein $^{27}$ & 1996 & Maximise detection of nodal metastases & $17-20$ \\
\hline Maurel $^{28}$ & 1998 & $\begin{array}{l}\text { Optimal ascription to node positive or node } \\
\text { negative categories }\end{array}$ & $8+$ \\
\hline Cserni $^{29}$ & 1999 & Maximise proportion of node positive cases & $6-16$ \\
\hline Wong $^{30}$ & 1999 & $\begin{array}{l}\text { Generate stage distribution comparable with } \\
\text { US National Cancer Data Base report }\end{array}$ & 14 \\
\hline Goldstein $^{31}$ & 2002 & Maximise detection of nodal metastases & All available \\
\hline Johnson ${ }^{32}$ & 2002 & $\begin{array}{l}\text { Conformity to American Joint Committee on } \\
\text { Cancer recommendations }\end{array}$ & 12 \\
\hline Cserni ${ }^{33}$ & 2002 & Reliability of node negative ascription & All available \\
\hline
\end{tabular}

Various studies have considered how many lymph nodes to examine. These are summarised in table $6 .^{26-33}$

Our study suggests that at least 10 nodes should be examined, but that ascertainment of stage $C$ disease is not improved by the examination of more than 15 nodes. However, setting an artificial "ceiling" on lymph node harvests by recommending minimum and maximum numbers has implicit dangers. Pathologists tend to initiate their lymph node harvest at the "high tie" and work towards the

\section{Take home messages}

- We assessed the quality of histopathology reporting and accuracy of Dukes's staging of colorectal cancers, comparing hospitals in the former South Western Health region with a "reference" hospital known to have high standards of reporting

- Standards of histopathology reporting and ascertainment of Dukes's stage C were significantly higher at the reference hospital

- Variations in ascertainment levels of Dukes's stage C disease mainly resulted from variations in the numbers of lymph nodes examined, and this could have serious consequences for individual patients, who may be denied life saving adjuvant chemotherapy

- Mean lymph node harvests above 10 would maximise the number of cases ascribed to Dukes's stage C, although lymph node harvests above 15 did not significantly increase the ascription to this stage tumour. Inevitably, therefore, probable reactive nodes, close to the high tie and away from the tumour, will be harvested first. If the minimum lymph node number is reached and no further dissection undertaken, then it is highly conceivable that the less than diligent pathologist will miss those nodes that are most likely to contain metastatic disease. Ultimately, we would concur with a recent comprehensive study of lymph node harvests, in a single USA centre, which found that there was no safe minimum number that could guarantee identification of node involvement, and which recommended that all lymph nodes in the lymphatic field of a colorectal cancer should be removed for histopathological assessment. $^{31}$

"For both the exemplar hospital and the others, the ascertainment of Dukes's stage C disease was highest when 10 to 14 lymph nodes were examined"

Inevitably the many studies that have assessed colorectal cancer lymph node harvests rely heavily on the technique used to obtain those lymph nodes. In general, in the UK at least, it is recommended that lymph nodes are harvested after adequate fixation and by "bacon slicing" the mesorectum/ mesocolon into $2-5 \mathrm{~mm}$ slices. We would particularly advocate removing the fatty tissues from the bowel wall first, although we would accept that this does make assessment of the extent of direct spread of the tumour, either towards a surgical margin, as in the rectum, or to the serosal aspect, more problematic, especially when harvesting nodes close to the tumour. Very few centres, in the UK at least, use fat clearing techniques, and there is evidence to indicate that these do not increase the yield of involved 
lymph nodes. ${ }^{34}$ Optimal harvests demand the motivation, and above all else, the time of the pathologist. We have no doubt that time and motivation, rather than individual methods, are the two most important factors to ensure adequate lymph node harvests. ${ }^{4}$

In conclusion, our study has shown that low lymph node harvests will lead to a reduction in the number of Dukes's C cases, which in turn has serious consequences for individual patients, who may be denied life saving adjuvant chemotherapy. The findings compliment others studies in the literature and show that mean lymph node harvests above 10 will maximise the number of cases ascribed to Dukes's stage C, although lymph node harvests above 15 did not significantly increase the ascription to this stage. In the UK, at least, determined efforts at education and the introduction of proforma reporting and datasets have improved the recording of important pathological prognostic data in colorectal cancer: we await further studies to determine whether the quality of that data has substantially improved.

\section{ACKNOWLEDGEMENTS}

We acknowledge with thanks all the histopathologists throughout the former South Western Health region who supplied pathology reports of colorectal cancer resection specimens for this audit.

\section{Authors' affiliations}

D F H Pheby, Unit of Applied Epidemiology, University of the West of England, Frenchay Campus, Coldharbour Lane, Bristol BS16 1QY, UK D F Levine, West Cornwall Hospital, St Clare Street, Penzance, Cornwall TR18 2PF, UK

R W Pitcher, Department of Histopathology, Royal Cornwall Hospital, Truro, Cornwall TR1 3L, UK

N A Shepherd, Department of Histopathology, Gloucestershire Royal Hospital, Great Western Road, Gloucester GL1 3NN, UK

\section{REFERENCES}

1 Executive NHS. Improving the quality of cancer services. HSC 2000/021 June 2001.

2 Quirke P, Williams GT. Minimum dataset for colorectal cancer histopathology reports. London: Royal College of Pathologists, 2000.

3 EUROCIM database v 3.0. Lyon: IARC, 1999.

4 Shepherd NA, Quirke P. Colorectal cancer reporting: are we failing the patient? J Clin Pathol 1997;50:266-7.

5 Pollock AM, Benster R, Vickers N. Why did treatment rates for colorectal cancer in South East England fall between 1982 and 1988? The effect of case ascertainment and registration bias. J Public Health Med 1995; 17:419-428.

6 Bull AD, Biffin AH, Melia J, et al. Colorectal cancer pathology reporting: a regional audit. J Clin Pathol 1997:50:138-42.

7 Woodman CB, Gibbs A, Scott N, et al. Are differences in stage at presentation a credible explanation for reported differences in the survival of patients with colorectal cancer in Europe? Br J Cancer 2001;85:787-90.

8 Gatta G, Capocaccia R, Sant M, et al. Understanding variations in survival for colorectal cancer in Europe: a EUROCARE high resolution study. Gut 2000;47:533-8.

9 Ponz de Leon M, Benatti P, Percesepe A, et al. Epidemiology of cancer of the large bowel-the 12-year experience of a specialized registry in northern Italy. Ital J Gastroenterol Hepatol 1999;31:10-18.
10 Ratto C, Sofo L, Ippoliti M, et al. Accurate lymph-node detection in colorectal specimens resected for cancer is of prognostic significance. Dis Colon Rectum 1999;42: 143-54.

11 NHS Executive. Guidance on commissioning cancer services: improving outcomes in colorectal cancer-the manual. London: Department of Health, October 2001.

12 Petersen VC, Baxter KJ, Love SB, et al. Identification of objective pathological prognostic determinants and models of prognosis in Dukes B colon cancer. Gut 2002:51:65-9.

13 Jass JR, Ajioka Y, Allen JP, et al. Assessment of invasive growth pattern and lymphocytic infiltration in colorectal cancer. Histopathology 1996;28:543-8.

14 Hermanek P, Giedl J, Dworak O. Two programmes for examination of regional lymph nodes in colorectal carcinoma with regard to the new $\mathrm{pN}$ classification. Pathol Res Pract 1989:185:867-73.

15 Cserni G, Tarjan M, Bori R. Distance of lymph nodes from the tumor: an important feature in colorectal cancer specimens. Arch Pathol Lab Med 2001;125:246-9.

16 Rigby K, Brown SR, Lakin G, et al. The use of a proforma improves colorectal cancer pathology reporting. Ann R Coll Surg Engl 1999;81:401-3.

17 Cross SS, Feeley KM, Angel CA. The effect of four interventions on the informational content of histopathology reports of resected colorectal carcinomas. J Clin Pathol 1998:51:481-2.

18 Wiese DA, Saha S, Badin J, et al. Pathologic evaluation of sentinel lymph nodes in colorectal carcinoma. Arch Pathol Lab Med 2000;124:1759-63.

19 Thorn M. Lymphatic mapping and sentinel node biopsy: is the method applicable to patients with colorectal and gastric cancer? Eur J Surg 2000;166:755-8.

20 Saha S, Wiese D, Badin J, et al. Technical details of sentinel lymph node mapping in colorectal cancer and its impact on staging. Ann Surg Oncol 2000:7:120-4.

21 Raraty MG, Winstanley JH. Variation in the staging of colorectal carcinomas: a survey of current practice. Ann R Coll Surg Engl 1998:80:188-91.

22 Compton CC, Henson DE, Hutter RV, et al. Updated protocol for the examination of specimens removed from patients with colorectal carcinoma. A basis for checklists. Arch Pathol Lab Med 1997;121:1247-54.

23 Jass JR. Future role of the pathologist in reporting colorectal cancer. World J Surg 1997;21:688-93.

24 Rayter Z, Leicester RJ, Mansi JL. Adjuvant chemotherapy for colorectal cancer. Ann R Coll Surg Engl 1995;77:81-4.

25 Ratkin GA. Adjuvant therapy for colon and rectal cancer. Am Fam Physician 1997:55:2487-92.

26 Hermanek P, Henson DE, Hutter RVP, et al. Appendix II. Colorectal carcinoma. UICC TNM supplement-a commentary on uniform use. Berlin: Springer-Verlag, 1993:69-71

27 Goldstein NS, Sanford W, Coffey M, et al. Lymph node recovery from colorectal resection specimens removed for adenocarcinoma; trends over time and a recommendation for a minimum number of lymph nodes to be recovered. Am J Clin Pathol 1996;106:209-16.

28 Maurel J, Launoy G, Grosclaude P, et al. Lymph node harvest reporting in patients with carcinoma of the large bowel: a French population-based study. Cancer 1998;82:1482-6.

29 Cserni G, Vajda K, Tarjan M, et al. Nodal staging of colorectal carcinomas from quantitative and qualitative aspects. Can lymphatic mapping help staging? Pathol Oncol Res 1999:5:291-6.

30 Wong JH, Severino R, Honnebier MB, et al. Number of nodes examined and staging accuracy in colorectal carcinoma. J Clin Oncol 1999;17:2896-900.

31 Goldstein NS. Lymph node recoveries from 2427 pT3 colorectal resection specimens spanning 45 years: recommendations for a minimum number of recovered lymph nodes based on predictive probabilities. Am J Surg Pathol 2002;26:179-89.

32 Johnson PM, Malatialian D, Porter GA. Adequacy of nodal harvest in colorectal cancer: a consecutive cohort study. J Gastrointest Surg 2002:6:883-8.

33 Cserni G Vinh-Hung V, Burzykowski T. Is there a minimum number of lymph nodes that should be histologically assessed for a reliable nodal staging of T3NOMO colorectal carcinomas? J Surg Oncol 2002;81:63-9.

34 Jass JR, Miller K, Northover JMA. Fat clearance method versus manual dissection of lymph nodes in specimens of rectal cancer. Int J Colorectal Dis 1986;1:155-6. 